\title{
Evaluation of abnormal uterine bleeding with transvaginal sonography
}

\author{
Monika Jain*, Saptrishi Chakraborty
}

Department of Obstetrics and Gynecology, Mahatma Gandhi Medical College and Hospital, Jaipur, Rajasthan, India

Received: 16 May 2017

Accepted: 02 June 2017

\section{*Correspondence:}

Dr. Monika Jain,

E-mail: tango_charlie700@yahoo.com

Copyright: (C) the author(s), publisher and licensee Medip Academy. This is an open-access article distributed under the terms of the Creative Commons Attribution Non-Commercial License, which permits unrestricted non-commercial use, distribution, and reproduction in any medium, provided the original work is properly cited.

\section{ABSTRACT}

Background: Abnormal uterine bleeding (AUB) is an important cause of health hazard in perimenopausal women. Accurate diagnosis for the causative factor of AUB in this age group is of utmost importance so that appropriate management can be established. Objective pf present study was to estimate the diagnostic accuracy, efficacy, sensitivity and specificity of transvaginal ultrasound in evaluation of uterine cavity lesion in perimenopausal women with abnormal uterine bleeding

Methods: This is a prospective study. This study was carried out in the Department of Obstetrics and Gynecology of Mahatma Gandhi Medical College and Hospital, Jaipur. We included 50 patients of perimenopausal age group who attended the gynecology department with the complaint of AUB. After selecting the patients who fulfill the eligibility criteria in the OPD detailed clinical history, obstetrical and gynecological history taken and detail clinical examination was done as per proforma followed by TVS.

Results: In the present study, maximum no of cases between age group of 40 to 44 with $48 \%$, and $38 \%$ of cases between age group of 45-49 yr. This suggests abnormal uterine bleeding is common in perimenopausal women. In present study overall sensitivity, specificity, PPV, NPV of TVS were $76 \%, 94 \%, 76 \%$ and $94 \%$.

Conclusions: In conclusion, abnormal uterine bleeding which often prevails as an important and common gynecological ailment. The Sensitivity, Specificity, PPV, NPV of TVS was 76\%, 94\%, 76\% and 94\%. The result showed that Transvaginal sonography has a moderate diagnostic accuracy in detecting endometrial hyperplasia and other intrauterine pathology. TVS is safe, acceptable and easily available in most secondary and tertiary care setting and is noninvasive. It should be continued as 1 st line diagnostic tool in patients with AUB in perimenopausal women.

Keywords: Abnormal uterine bleeding, Histopathology, Transvaginal ultrasonography

\section{INTRODUCTION}

Abnormal uterine bleeding is defined as any deviation from the normal menstrual cycle this include change in regularity, frequency of menses, duration or amount of bleeding during or in between periods. ${ }^{1,2}$

AUB is responsible for $20-30 \%$ of patient who attend gynaec outpatient department amongst women in reproductive age group and $50 \%$ in a perimenopausal women $^{3}$ and significantly impacting quality of life and imposing financial burden. ${ }^{4}$
Goldstein et al has defined AUB as patients having either metrorrhagia defined as vaginal bleeding separated from expected menses or menorrhagia defined as patients' subjective complaints of either increased duration or increased volume of flow or both. ${ }^{5}$

The International Federation of Gynecology and Obstetrics working group on menstrual disorders has proposed a classification system (PALM-COEIN) for causes of the AUB in women. ${ }^{6}$ There are nine main categories, which are arranged according to the acronym PALM-COEIN: Polyp; adenomyosis; leiomyoma; 
malignancy and hyperplasia; coagulopathy; ovulatory dysfunction; endometrial; iatrogenic; and not yet classified. According to the proposed classification system, non-specific.

AUB has been investigated with detail clinical history and clinical evaluation. There are various tools for diagnosis of AUB in perimenopausal women are TVS, Saline Sonography, and Hysteroscopy and confirmed on histopathology report.

TVS is an inexpensive, non-invasive and a convenient way to assess the uterine pathology Therefore, it is recommended as a $1^{\text {st }}$ line diagnostic tool for assessing uterine pathology in perimenopausal age women presenting with AUB. AUB in perimenopausal age group is critical, an ideal diagnostic test should be non-invasive or minimally invasive is easily acceptable to the patient's low cost high sensitivity and specificity.

In this study after detail clinical and physical examination, TVS was done in AUB patient and compare the sensitivity, specificity and efficacy of TVS in diagnosis and to correlate the TVS finding with histopathology.

Objectives of present study were to estimate the diagnostic accuracy of two-dimensional transvaginal ultrasound in evaluation of uterine cavity lesion in perimenopausal women with abnormal uterine bleeding and estimate the efficacy of transvaginal sonography in diagnosis of intracavitary lesion in perimenopausal women with abnormal uterine bleeding. The sensitivity and specificity of transvaginal sonography diagnosing intrauterine pathology in abnormal uterine bleeding.

\section{METHODS}

This is prospective study is conducted in department of Obstetrics and Gynecology in Mahatma Gandhi Hospital, Jaipur from February 2015 to October 2016. This study was done on women presenting to the gynecological OPD with complain of abnormal uterine bleeding in perimenopausal age group were invited to participate in the study.

The inclusion and exclusion criteria were applied and the women who were eligible to participate and who give written consent were enrolled in the study.

A total of 50 women who met the inclusion criteria were selected and after explaining the procedure, the consent form explained in their own language was signed.

\section{Inclusion criteria}

Patient having following characteristic were included
- Having abnormal uterine bleeding

- Uterus less than 12 weeks size.

\section{Exclusion criteria}

- Acute pelvic infection

- Uterus more than 12-week size

- Pregnant women

- Vaginal or cervical cause of bleeding

- Bleeding disorder

- Any drug intake

After selecting the patients who fulfill the eligibility criteria in the OPD detailed clinical history, obstetrical and gynecological history taken and detail clinical examination was done as per proforma.

Per speculum examination was done to note abnormal discharge, erosion, cervical hypertrophy or cervical polyp. A per vaginal examination was done to know about any uterine cervical and adnexal abnormality.

Laboratory investigations including $\mathrm{CBC}$, coagulation profile, random blood sugar, liver and kidney function and pregnancy test done. All the eligible patients were subjected to transvaginal sonography. Patient was subjected to ultrasound examination in the department of radiology in Mahatma Gandhi hospital.

After tabulating the findings of TVS it was compared with histopathology and the sensitivity, specificity, PPV and NPV of TVS were calculated.

\section{RESULTS}

A prospective study conducted on 50 perimenopausal women with abnormal uterine bleeding to evaluate the efficacy and accuracy of Transvaginal sonography and Hysteroscopy.

Table 1: Distribution of patient according to age group.

\begin{tabular}{|lll|}
\hline Age & No. of patients & Percentage \\
\hline $40-44$ & 24 & 48 \\
\hline $45-49$ & 19 & 38 \\
\hline $50-55$ & 7 & 14 \\
\hline Total & 50 & 100 \\
\hline
\end{tabular}

Out of 50 patients in this study ranged from 40-55 yr. mean age was yr. Majority of patient were in age group of $40-44$ yrs. (48\%) and minimum $14 \%$ in age group of 50-55 yr.

The proportion of patient in present study among all age group categories 40-44 yrs., 45-49 yrs., 50-55 yrs. i.e. $48 \%, 38 \%, 14 \%$.

- $\quad$ Perimenopausal age group (40-55) 
Table 2: Relation of type of bleeding and TVS findings.

\begin{tabular}{|llllll|}
\hline $\begin{array}{l}\text { Endometrial thickness } \\
(\mathbf{m m})\end{array}$ & Menstrual symptoms & & HPB & Irregular \\
\hline$<5$ & 1 & IMB & Frequent & 0 & 0 \\
\hline $6-9$ & 14 & 1 & 0 & 2 & 2 \\
\hline $10-14$ & 6 & 2 & 3 & 0 & 2 \\
\hline $15-19$ & 2 & 4 & 3 & 0 & 1 \\
\hline$>20$ & 2 & 1 & 1 & 0 & 6 \\
\hline Total & 25 & 1 & 1 & 2 & 6 \\
\hline
\end{tabular}

In present study, correlation of patient's menstrual symptom with endometrial thickness was done. Out of 25 cases of Heavy menstrual bleeding maximum no of patient 14 had ET between 6-9 mm, 6 patients had ET between $10-14 \mathrm{~mm}, 2$ patients had heavy menstrual bleeding with ET> $20 \mathrm{~mm}$, on histopathology one of patient had atypical hyperplasia and one patient also had atypical hyperplasia on ET "Between" 15-19.

9 patients of intermenstrual bleeding, 4 patients had ET Between 10-14. 8 patients of frequent bleeding, 3 patients had ET between 6-9mm, 3 patients had ET 10-14mm, 1 had ET between $15-19 \mathrm{~mm}$, and 1 had ET> $20 \mathrm{~mm}$. 6 patients of irregular bleeding 2 had ET 6-9 mm, 2 had ET between 10-14 mm and 1 patient had ET "Between" 1519 and 1 had ET> $20 \mathrm{~mm}$.

Table 3: Diagnosis of endometrial pathology in AUB patient with TVS.

\begin{tabular}{|lll|}
\hline $\begin{array}{l}\text { Endometrial findings } \\
\text { on TVS }\end{array}$ & $\begin{array}{l}\text { No. of } \\
\text { cases }\end{array}$ & Percentage \\
\hline Normal & 25 & 50 \\
\hline Endometrial hyperplasia & 12 & 24 \\
\hline Endometrial polyp & 7 & 14 \\
\hline Sub mucosal fibroid & 4 & 8 \\
\hline Adenomyosis & 2 & 4 \\
\hline Total & 50 & 100 \\
\hline
\end{tabular}

Table 4: Endometrial thickness on TVS in relation to histopathology.

\begin{tabular}{|llllllll|}
\hline $\begin{array}{l}\text { Endometrial } \\
\text { thickness }\end{array}$ & Total & \multicolumn{6}{l|}{ Histopathological findings } \\
& normal & EH & EP & SMF & A \\
\hline$<5$ & 2 & 2 & & & & \\
\hline $6-9$ & 23 & 16 & 2 & 1 & 2 & 2 \\
\hline $10-14$ & 15 & 6 & 5 & 1 & 2 & 1 \\
\hline $15-19$ & 5 & & 2 & 3 & & \\
\hline$>20$ & 5 & & 2 & 3 & & \\
\hline Total & 50 & 24 & 11 & 8 & 4 & 3 \\
\hline
\end{tabular}

Out of total 50 cases, 2 patient had ET $<5 \mathrm{~mm}$ which were normal on histopathology.

23 patients showed endometrial thickness 6-9 $\mathrm{mm}$ on TVS, of which 16 cases were normal on histopathology,
2 cases had endometrial hyperplasia, 1 case had polyp, 2 cases had sub mucosal fibroid and 2 cases had adenomyosis.

15 cases showed ET 10-14 mm, of which 6 cases were normal, 5 cases of endometrial hyperplasia, 1 case of endometrial polyp, 1 case of adenomyosis and 2 case of sub mucosal fibroid were confirmed on histopathology. 5 cases showed ET 15-19mm. Out of which 3 cases were of endometrial polyp and 2 cases of endometrial hyperplasia.

5 cases showed ET $>20 \mathrm{~mm}$ on TVS out of which 2 cases had endometrial hyperplasia and 3 were of endometrial polyp.

Table 5: Finding of transvaginal sonographic diagnosis compared with HPR.

\begin{tabular}{|lllllll|}
\hline TVS & No. of & \multicolumn{7}{l|}{ Histopathological findings } \\
\cline { 2 - 7 } findings & Pts. & Normal & EH & EP & SMF & A \\
\hline Normal & 25 & 20 & 1 & 2 & 1 & 1 \\
\hline EH & 12 & 1 & 9 & 1 & & 1 \\
\hline EP & 7 & 1 & 1 & 5 & & \\
\hline SMF & 4 & 1 & & & 3 & \\
\hline A & 2 & 1 & & & & 1 \\
\hline Total & 50 & 24 & 11 & 8 & 4 & 3 \\
\hline
\end{tabular}

In present study, out of 50 cases total 25 cases had normal endometrium on TVS, of which 20 cases had normal endometrial finding on histopathology, 1 case diagnosed as endometrial Hyperplasia, 2 cases as endometrial polyp, one case as sub mucosal fibroid and one case as adenomyosis showed on histopathology after hysterectomy.

Endometrial hyperplasia was found on TVS in 12 cases, of which 9 cases were diagnosed as endometrial hyperplasia 1 case showed normal endometrium, 1 case had endometrial polyp, 1 case had Adenomyois on histopathology.

Endometrial polyp was found on TVS in 8 cases. Of which 5 cases had polypoidal endometrium, 1 case had normal and 1 case had endometrial hyperplasia on histopathology. 
Sub mucosal fibroid was found on TVS in 4 cases, of which 3 cases had sub mucosal fibroid and 1 case had normal endometrium on histopathology.

Adenomyosis was diagnosed by TVS and 2 cases missed out of which 1 was normal and 1 was endometrial hyperplasia on TVS and 1 case misdiagnosed as adenomyosis which was normal on histopathology.

Table 6: Finding of sensitivity, specificity, PPV, NPV of TVS.

\begin{tabular}{|lllll|}
\hline & Sensitivity & Specificity & PPV & NPV \\
\hline Normal & 83.33 & 80.76 & 80 & 84 \\
\hline EH & 81.81 & 92.3 & 75 & 94.73 \\
\hline EP & 62.5 & 95.23 & 71.42 & 93.02 \\
\hline Adenomyosis & 33.33 & 97.87 & 50 & 95.83 \\
\hline SMF & 75 & 97.82 & 75 & 97.82 \\
\hline
\end{tabular}

Sensitivity, specificity, PPV, NPV for EH was $81.81 \%$, $92.3 \%, \quad 75 \%, \quad 94.73 \%$ respectively. Sensitivity, specificity, PPV, NPV for polyp 62.5\%, 95.23\%, 71.42\%, $93.02 \%$. Sensitivity, specificity, PPV, NPV for SMF 75\%, 97.82\%, 75\%, 97.82\%. Sensitivity, specificity, PPV, NPV for adenomyosis 33.33\%, 97.87\%, 50\%, $95.83 \%$.

Table 7: Diagnosis of endometrial pathology in AUB patients by TVS, confirmed on HPR.

\begin{tabular}{|llll|}
\hline $\begin{array}{l}\text { Final } \\
\text { Diagnosis }\end{array}$ & $\begin{array}{l}\text { Diagnosed } \\
\text { by TVS }\end{array}$ & $\begin{array}{l}\text { Diagnose } \\
\text { by HPR }\end{array}$ & $\%$ \\
\hline $\begin{array}{l}\text { Normal } \\
\text { endometrium }\end{array}$ & 25 & 24 & 48 \\
\hline $\begin{array}{l}\text { Endometrial } \\
\text { hyperplasia }\end{array}$ & 12 & 11 & 22 \\
\hline $\begin{array}{l}\text { Endometrial } \\
\text { polyp }\end{array}$ & 7 & 8 & 16 \\
\hline $\begin{array}{l}\text { Sub mucosal } \\
\text { fibroid }\end{array}$ & 4 & 4 & 8 \\
\hline Adenomyosis & 2 & 3 & 6 \\
\hline
\end{tabular}

Out of 50 cases of AUB patient, majority of patients had normal endometrial finding in $48 \%$ on histopathology followed by endometrial hyperplasia (22\%), endometrial polyp $16 \%$ and sub mucosal fibroid and adenomyosis less comparatively $8 \%, 6 \%$ respectively.

\section{DISCUSSION}

Abnormal uterine bleeding most common gynecological complaint among women in perimenopausal age group.

The study was conducted on 50 women of perimenopausal age group (40 to 55yr) presenting to Mahatma Gandhi hospital Jaipur who fulfilled the eligibility criteria. After taking detailed history, physical examination and investigations, TVS was done in all patients. These finding further compared with histopathological report.

\section{Distribution of age group}

Analysis of patient according to age revealed in our study that maximum no of cases between age group of 40 to 44 with $48 \%$, and $38 \%$ of cases between age group of $45-49$ yr. This suggests abnormal uterine bleeding is common in perimenopausal women.

Varadarajan $\mathrm{R}$ in their study they reported maximum number of cases $(56.0 \%)$ belonged to the age group $40-$ 43 yrs. $^{7}$ Verma U also observed $41 \%$ of cases belong to age group in 44 to 47 years. $^{8}$

\section{Endometrial thickness on TVS}

Transvaginal sonography is effective method for the evaluation of endometrium in perimenopausal and postmenopausal women. The endometrium can be easily visualized by ultrasonography and measurement of its thickness can be used as a screening method.

In present study on TVS at endometrial thickness 5 to 8 $\mathrm{mm}$, no endometrial pathology was found this was compared with other studies. Veena BT revealed normal endometrium in $45 \%$ (majority of these patients had endometrial thickness less than $9 \mathrm{~mm}$ ). ${ }^{9}$

In most of studies it revealed that endometrial thickness of $8 \mathrm{~mm}$ could be taken as cut off in perimenopausal women and in our study the similar finding was observed.

\section{Abnormal Endometrial finding on TVS}

In my study analysis of patient according to abnormal finding on TVS showed different endometrial finding and TVS finding compared with histopathological findings.

In present study, endometrial hyperplasia by TVS was found in 12 cases, on comparison with histopathology report 9 case truly diagnosed by TVS and 2 cases missed and 3 cases misdiagnosed out of which one was normal, one was endometrial polyp and one was adenomyosis on histopathology report.

Endometrial polyp was found on TVS in 7 cases, on comparison with histopathology 5 cases identified as truly on TVS and 3 cases missed by TVS and 2 cases misdiagnosed out of which 1 case had normal endometrium and 1 case had endometrial hyperplasia on histopathology.

Sub mucosal fibroid was found on TVS in 4 cases on comparison with histopathology 3 cases had sub mucosal fibroid and 1 case had normal endometrium on histopathology, and one case misdiagnosed as SMF which was normal on histopathology.

Adenomyosis was diagnosed by TVS in 2 cases (4\%), on histopathology report 3 cases of adenomyosis were found 2 cases missed out of which 1 was normal and 1 was 
endometrial hyperplasia on TVS and 1 case misdiagnosed as adenomyosis which was normal on histopathology. Similar study was found in Bhosle they showed simple hyperplasia in $17.8 \%$ of cases. ${ }^{10}$ Takreem reported $15 \%$ of cases of endometrial hyperplasia among 100 perimenopausal women. ${ }^{11}$

Damle RP showed endometrial hyperplasia (23.86\%) which is in concordance with Slobada L (22.6\%), Dangal G $(23 \%){ }^{12,13}$ Khare, $(36.2 \%)$, Doroiswami S (68\%) observed high incidence of endometrial hyperplasia in perimenopausal age group. ${ }^{14,15}$ In present study the sensitivity, specificity, PPV, NPV for diagnosis of endometrial hyperplasia on TVS was $81.81,94.43 \%$, $90 \%, 95 \%$ which correlate with Shokouhi B. ${ }^{16}$

The accuracy, sensitivity, specificity, PPV, and NPV were $88.25 \%, 90.7 \%, 84 \%, 97.7 \%$, and $84 \%$ in premenopausal women in AUB patient specially in endometrial hyperplasia. Aslam reported sensitivity and specificity $81.3 \%, 73.6 \%$ respectively. ${ }^{17}$ Vercellini et al showed sensitivity and specificity of TVS was $96 \%$ and $86 \%$ respectively.

\section{CONCLUSION}

In conclusion, this study demonstrates Transvaginal ultrasonography is a widely available, relatively cheap and practical method to evaluate uterine pathologies. It is non-invasive and minimal discomfort to the patient. Therefore, it is mostly used as the initial modality in patients with abnormal uterine bleeding or non-bleeding symptomatic patients. Its relative simplicity and availability makes it a very helpful tool for screening.

In conclusion, abnormal uterine bleeding which often prevails as an important and common gynecological ailment in my study $48 \%$ patient had normal endometrium, and $52 \%$ had abnormal uterine endometrial finding, out of which endometrial hyperplasia found in $22 \%$, Polyp in $16 \%$, sub mucosal Fibroid in $8 \%$, and adenomyosis in $6 \%$ of cases.

Both TVS and hysteroscopy can detect endometrial intracavitary abnormalities with varying accuracies. The Sensitivity, Specificity, PPV, NPV of TVS was $76 \%$, $94 \%, 76 \%$ and $94 \%$.

The result showed that Transvaginal sonography has a moderate diagnostic accuracy in detecting endometrial hyperplasia and other intrauterine pathology. TVS is safe, acceptable and easily available in most secondary and tertiary care setting and is noninvasive. It should be continued as 1st line diagnostic tool in patients with AUB in perimenopausal women

Funding: No funding sources Conflict of interest: None declared

Ethical approval: The study was approved by the Institutional Ethics Committee

\section{REFERENCES}

1. Vilos GA, Marks J, Tureanu V, Abu-Rafea B, Vilos AG. The levonorgestrel intrauterine system is an effective treatment in selected obese women with abnormal uterine bleeding. J Minimally Invasive Gynecol. 2011;18(1):75-80.

2. Speroff L, Fritz MA. Clinical gynecologic endocrinology and infertility. Lippincott Williams Wilkins; 2005.

3. Oriel KA, Schrager S. Abnormal uterine bleeding. Am Fam Physician. discussion 1381-2. 1999;60(5):1371-80.

4. Fraser IS, Langham S, Uhl-Hochgraeber K. Healthrelated quality of life and economic burden of abnormal uterine bleeding. Expert Rev Obstet Gynecol. 2009;4(2):179-89.

5. Goldstein SR, Zeltser I, Horan CK, Snyder JR, Schwartz LB. Ultrasonography-based triage for perimenopausal patients with abnormal uterine bleeding. Am J Obstet Gynecol. 1997;177(1):102-8.

6. Munro MG, Critchley HO, Fraser IS, FIGO Menstrual Disorders Working Group. The FIGO classification of causes of abnormal uterine bleeding in the reproductive years. Fertil Steril. 2011;95(7):2204-8.

7. Varadarajan R, Sreekantha SM. Role of hysteroscopy in abnormal uterine bleeding in perimenopausal age group. J Evol Med Dent Sci. 2013;2(10):1504-9.

8. Verma U, Garg R, Singh S, Yadav P, Rani R. Diagnostic approach in perimenopausal women with abnormal uterine bleeding. J South Asian Federation Menopause Societies. 2014;2(1):12-4.

9. Veena BT, Shivalingaiah N. Role of transvaginal sonography and diagnostic hysteroscopy in abnormal uterine bleeding. JCDR. 2014;8(12):OC06.

10. Bhosle A, Fonseca M. Evaluation and histopathological correlation of abnormal uterine bleeding in perimenopausal women. Bombay Hospital J. 2010;52(1):69-72.

11. Takreem A, Danish N, Razaq S. Incidence of endometrial hyperplasia in 100 cases presenting with polymenorrhagia/menorrhagia in perimenupausal women. J Ayub Med Coll Abbottabad. 2009;21(2):60-3.

12. Sloboda L, Molnar E, Popović Z, Zivković S. Analysis of pathohistological results from the uterine mucosa 1965-1998 at the gynecology department in Senta. Medicinski pregled. 1998;52(6-8):263-5.

13. Dangal G. A study of endometrium of patients with abnormal uterine bleeding at Chitwan Valley. Kathmandu Univ Med J. 2003;1(2):110-2.

14. Khare A, Bansal R, Sharma S, Elhence P, Makkar N, Tyagi Y. Morphological spectrum of endometrium in patients presenting with dysfunctional uterine bleeding. People's J Scientific Res. 2012;5(2):13-16.

15. Doraiswami S, Johnson T, Rao S, Rajkumar A, Vijayaraghavan J, Panicker VK. Study of endometrial pathology in abnormal uterine bleeding. J Obstet Gynecol India. 2011;61(4):426. 
16. Shokouhi B. Role of transvaginal ultrasonography in diagnosing endometrial hyperplasia in pre-and postmenopause women. Nigerian Medical J. 2015;56(5):353.

17. Aslam M, Ijaz L, Tariq S, Shafqat K. Comparison of transvaginal sonography and saline contrast sonohysterography in women with abnormal uterine bleeding: correlation with hysteroscopy and histopathology. Int J Health Sci. 2007;1(1):17.

Cite this article as: Jain M, Chakraborty S.

Evaluation of abnormal uterine bleeding with transvaginal sonography. Int J Reprod Contracept Obstet Gynecol 2017;6:2794-9. 